\title{
ESPIRITUALIDADE E SAÚDE NA LOGOTERAPIA DE VICTOR FRANKL
}

\author{
SPIRITUALITY AND HEALTH IN VICTOR FRANKL'S LOGOTHERAPY
}

Paulo SÉrgio Carrara ${ }^{(*)}$

\begin{abstract}
RESUMO
Victor Frankl criou uma escola de psicologia que evidencia a vontade de sentido como motivação primária do ser humano, a Logoterapia. A perda dessa vontade de sentido seria causa de neuroses pessoais e do que ele chama neurose coletiva, caracterizada pelo vazio existencial. Na origem de vários distúrbios psicológicos atuais se encontra esse vazio existencial, a ser enfrentado no processo psicoterapêutico em vista de uma vida mais saudável psiquicamente. A Logoterapia de Frankl traz abordagem original da relação Psicologia e Religião, ultrapassando visões psicológicas mais negativas da Religião. A dimensão espiritual do ser humano se encontra no seu próprio inconsciente e sua repressão também se mostra neurotizante. O presente artigo avalia a pertinência da proposta de Frankl sobre a relação espiritualidade e saúde. Em um momento de exploração religiosa da fragilidade emocional das pessoas, sua abordagem oferece pistas excelentes para uma compreensão mais consistente da complexa relação entre espiritualidade e saúde, haja vista sua significativa contribuição para a humanização na saúde e no cuidado integral.
\end{abstract}

PALAVRaS-Chave: Logoterapia. Victor Frankl. Espiritualidade. Saúde psíquica.

\begin{abstract}
Victor Frankl created a psychological school that demonstrated the will for meaning as the primary motivation of the human being, logotherapy. The loss of this will for meaning would then be the cause of personal neuroses and of what he calls the collective neurosis, characterized by an existential emptiness. In the origin of various current psychological disturbances this existential emptiness can be found, which in turn needs to be confronted by a process of psychotherapy that seeks a more healthy psychological life. Frankl's logotherapy suggests a rather original approach regarding the relationship of psychology and religion, surpassing psychological visions typically negative towards religion. The spiritual dimension of the human person is found in her/his own unconscious and repression is shown to be neurotic. This present study evaluates the relevance of Frankl's proposal with regards to the relationship between spirituality and health. In a time of religious exploration of the emotional fragility of persons, this approach suggests excellent clues for a more solid comprehension of the complex relationship between spirituality and health.
\end{abstract}

KEYWORDS: Logotherapy. Victor Frankl. Spirituality. Psychic Health.

\section{INTRODUÇÃO}

Victor Frankl ${ }^{1}$ diagnosticou o mal-estar psicológico do homem pós-moderno como frustração existencial. Formulou o conceito de um novo tipo de neurose: a

(*) Doutor em teologia pela FAJE. Professor nessa mesma Faculdade e no Instituto Santo Tomás de Aquino (ISTA), em Belo Horizonte. Membro do Grupo de Pesquisa Estudos em Cristologia da FAJE. País de origem: Brasil. E-mail: p-paulus2011@hotmail.com.

${ }^{1}$ Victor Frankl nasceu em 1905 e morreu em 1997. Psiquiatra vienense, de origem hebraica, sofreu a perseguição nazista e passou três anos em campos de concentração. Experiência que lhe permitiu repensar princípios da psicanálise e criar uma nova escola de psicologia, a logoterapia (FIZZOTTI; SALUSTRI, 2001, p. 219-221). 
neurose existencial, neurose noogênica que, de tão comum, também pode ser chamada neurose coletiva, uma vez que atinge grande número de pessoas, caracterizando-se como neurose de massa. O pensamento do psiquiatra nos permite uma aproximação ao problema psicológico em tempos pós-modernos, onde o niilismo atinge seu mundo afetivo com dramáticas consequências para a sua saúde física, psíquica e espiritual. Por outro lado, Victor Frankl, ao contrário de outros estudiosos da relação entre Religião e Psicologia, vê a religião como fator positivo no processo de cura das neuroses. Embora desnecessária para uma vida com sentido, a religião aporta à existência humana um plus capaz de fortalecê-la em diversos aspectos a partir de um sentido de totalidade.

Nosso autor utiliza o termo religião quase sempre no sentido de espiritualidade, pois, apesar de ser judeu, não se refere a nenhuma religião específica ou crença religiosa. A religião ou espiritualidade dizem respeito à abertura do ser humano à transcendência. Segundo ele, "religião tem pouco a ver com estreiteza confessional", pois Deus não se limita a uma "denominação determinada". Para o psiquiatra, é inconcebível que uma igreja ou religião imponha suas crenças, pois essas devem ser livremente aceitas pelo homem religioso (FRANKL, 1997, p. 62-63) . Os termos religião e espiritualidade aludem, portanto, a uma mesma realidade no pensamento de Frankl. Nesse artigo buscamos avaliar a relação entre espiritualidade e saúde, mostrando sua pertinência na ótica da escola de psicologia criada pelo psiquiatra, a Logoterapia.

\section{A BUSCA DE SENTIDO SEGUNDO VICTOR FRANKL}

Uma das grandes contribuições de Frankl para a Psicologia e para a Antropologia se encontra na descoberta da vontade de sentido, considerada por ele motivação primária no ser humano e não apenas racionalização secundária de impulsos instintivos (FRANKL, 2006, p. 93). Tal vontade de sentido está relacionada com a capacidade que tem o ser humano para decidir e ser responsável. Segundo Freud, o ser humano é movido por impulsos inconscientes; já para Frankl, o propriamente humano começa onde começa a liberdade e a responsabilidade (FRANKL, 1997, p. 19). Sem negar os impulsos

\footnotetext{
${ }^{2}$ A religiosidade, segundo Libanio, tem a ver com o sentimento religioso e a ligação com algo que se distinga do próprio eu. A espiritualidade diz respeito à experiência do sagrado, que se faz segundo o universo simbólico de uma religião, a partir de um sistema doutrinal e normativo, vivido e transmitido por uma comunidade. A experiência de Deus - a espiritualidade - tem sempre a ver com a percepção íntima de que Deus é o horizonte último da existência e tende a se expressar numa religião determinada (LIBANIO, 2002, p. 87-109).
} 
inconscientes descritos pela psicanálise freudiana, o psiquiatra avança ao afirmar a responsabilidade e liberdade do ser humano frente a estes impulsos. Liberdade sempre limitada, por um lado, mas jamais inexistente, por outro.

Todos os conceitos da teoria de Frankl baseiam-se na questão do sentido, afinal o ser humano se move em busca de um sentido para sua existência. Tratase de um interesse primário presente em todas as pessoas. Da satisfação desse interesse primário depende a realização da própria vida (FRANKL, 1989, p. 23). Todo ser humano precisa aportar à sua existência algo que tenha a ver com o sentido para que a felicidade se torne efetiva, já que ela não se encontra apenas na satisfação material ou no prazer sexual, segundo o que afirma o niilismo pósmoderno. O sentido tem sempre a ver com uma maneira de encarar a vida (LUKAS, 1990, p. 15). Para a Logoterapia, o sentido consiste na capacidade de dar forma a uma situação específica, seja ela qual for. Viver com sentido significa, com suas aptidões, emoções e vontade, pôr-se a serviço de uma tarefa, dentro de uma circunstância determinada que exija engajamento. A vontade de sentido orienta o ser humano a um para quê, que pode ser sempre encontrado, em qualquer situação, mesmo no sofrimento. Desse para quê depende, em última análise, o fracasso ou o sucesso da vida humana (LANGLE, 1992, p. 1314).

A realização do sentido acontece através da atuação de valores, que se dividem em três tipos: experienciais, criativos e atitudinais. De acordo com Frankl, são maneiras de encontrar sentido para determinada situação: fazer uma experiência que, em si, é positiva e se justifica, ou amar alguém, aqui se encontram os valores experienciais; criar uma obra ou se dedicar a um trabalho assumido com motivações consistentes, através de valores criativos; assumir uma atitude diante de um sofrimento inevitável, o que depende dos valores atitudinais (FRANKL, 2006, p. 100). A vontade de sentido se expressa na vida do ser humano a partir dessas três classes de valores. Mas e quando a vontade de sentido se frustra? E quando o ser humano não consegue realizar essa sua motivação primária? Acaba se entregando ao desânimo e cai no vazio existencial, que tão drasticamente caracteriza nosso tempo. $\mathrm{O}$ vazio existencial se apresenta como a doença de nossos dias, podendo originar neurose e depressão ou ao menos contribuir para o agravamento de doenças psicológicas.

\section{O VAZIO EXISTENCIAL COMO NEUROSE}

Segundo Frankl, o ser humano se revela diverso dos animais também quanto a seus instintos. No animal, os instintos indicam o que ele deve fazer; sem 
autoconsciência, esse não distingue valores e vive de acordo uma lei natural intrínseca que o move em todas as direções. Já o ser humano carece de metas, valores que o orientem. Durante séculos valores e tradições guiaram o homem, porque nascia em uma sociedade com normas fixas predeterminadas que organizavam a vida em termos de valores. Hoje esta estrutura está comprometida pelo niilismo (FRANKL, 1998, p. 95). O ser humano se sente à deriva e encontra dificuldade para criar referências próprias para sua subjetividade:

O niilismo é a negação do sentido, porque considera impossível não só a fé em um sentido supremo, mas em qualquer sentido. É, assim, caracterizado por um ceticismo axiológico, o qual é acompanhado invariavelmente por um relativismo axiológico (FRANKL, 2001b, p. 104).

Para o filósofo Franco Volpi, o relativismo ético acaba provocando crescimento da crença na ciência e na técnica, que regulam a vida no planeta com suas descobertas, análises e previsões. Apesar de haver aspectos positivos nos avanços científicos, quando os valores são substituídos pela ciência e a técnica, "os imperativos morais lembram freios de bicicleta, usados em avião a jato" (VOLPI, 1999, p. 140). Os valores, quando muito, são assumidos na vida pessoal, mas incidem pouco no coletivo. Nesse caso, "a ética e a moral têm a beleza de fósseis raros." (VOLPI, 1999, p. 140).

Duas são as consequências da perda de valores para o ser humano: ou faz o que os outros fazem, o que se traduz no conformismo do Ocidente, ou faz o que os outros o obrigam a fazer, o que se enquadra no totalitarismo oriental (FRANKL, 1998, p. 95). O homem atual se situa entre relativismos e absolutismos, o que provoca falta de orientação gerada pela sensação de vazio existencial, em crescente difusão entre os que procuram ajuda psicológica. Trata-se de uma queixa apresentada por muitos: uma frustração que se manifesta como falta de conteúdo para a existência. Muitas pessoas procuram o psicólogo ou psiquiatra exatamente porque duvidam de um sentido para sua vida.

Alguns fenômenos desviantes da sociedade pós-moderna emergem como consequência da frustração do sentido que enfraquece a liberdade e o reconhecimento da própria responsabilidade. Segundo a Logoterapia, a toxicodependência e o alcoolismo estão, ao menos em parte, ligados ao vazio existencial. Estudos realizados chegaram a esta conclusão, mostrando que a apatia com relação à vida oferece a base para a instalação da dependência, o que não quer dizer que fatores intrapsíquicos não estejam na origem destes 
transtornos, mas, mesmo nestes casos, verifica-se certo vazio existencial. A depressão também emerge como consequência do vazio existencial. De fato, parece impossível explicar o aumento desta doença nos termos da psicopatologia tradicional. Nem sempre surge tendo como causa conflitos internos ou causas endógenas. Sem generalizar e com prudência, pode-se constatar que o aumento da depressão se tornou o sintoma mais evidente do vazio existencial (FIZZOTTI, 2002, p. 117-141).

De acordo com uma pesquisa realizada nos Estados Unidos, um dos fatores que eleva o nível da insatisfação entre os estudantes se encontra no modo como lhes são apresentadas as novas descobertas científicas. Um modo absolutamente reducionista e materialista. São doutrinados com uma teoria mecanicista do ser humano e com uma filosofia relativista da vida (FRANKL, 1998, p. 97), em que seus sentimentos e valores passam despercebidos. O clima de vazio existencial entre os jovens favorece também o adoecimento da libido sexual. Quando a aspiração por um sentido para a vida se frustra, eles começam a buscar compensações em experiências sexuais. O excesso de erotização da sociedade pós-moderna também se relaciona, portanto, com a frustração do sentido (FRANKL, 2001a, p. 144). O niilismo acaba tornando o prazer sexual um dos últimos refúgios do absoluto.

$O$ vazio existencial não se enquadra no conceito de neurose psicogênica. Não tem origem em problemas intrapsíquicos. Nem se apresenta como efeito de uma neurose. Victor Frankl o caracteriza como neurose noogênica, diversa do que a psicanálise clássica define como neurose. Surge de problemas morais ou éticos, de questões existenciais. Não se situa no conflito entre o superego e o ego, mas entre o superego e a verdadeira consciência, que não se identifica com o superego, como supõe a psicanálise, porque se trata daquela dimensão na qual o ser se percebe a si mesmo como necessitado de referências éticas para viver (FRANKL, 1998, p. 100-101). O mérito de Frankl está em descobrir o estreito nexo entre a orientação de sentido interna da pessoa e sua saúde psíquica, até então desconhecida pela psicologia (LUKAS, 1992a, p. 16). Um nexo gerador de uma nova neurose, cuja característica principal se encontra exatamente no vazio existencial, na frustração da vontade de significado.

Segundo Fizzotti (2002, p. 228-229), o diagnóstico "esgotamento nervoso" era usado, até bem pouco tempo, para os mais variados problemas psicológicos e até para as psicoses mais brandas. Com a evolução da Psicologia, os diagnósticos se tornaram mais adequados. Mas a tendência da moda prevaleceu durante anos. Os próprios pacientes usavam o termo esgotamento nervoso para explicar seus sintomas. Depois veio o período dos “complexos”. Qualquer 
problema afetivo mais simples era designado como complexo. Agora estamos na era do stress. Principalmente os que pertencem a um nível sociocultural mais elevado reclamam do stress da vida moderna. Em nossa época, no entanto, difunde-se cada vez mais o autodiagnostico crise existencial. Claro que há muitos problemas psicológicos que não pertencem a essa classificação, porém aumenta o número daqueles que se lamentam de uma vida sem sentido. Embora não tendo significado unívoco, muitas vezes tal queixa denota falta de objetivos, de tarefas, de empenhos criativos. Neste caso se pode falar de uma neurose de sentido, caracterizada por um vazio existencial, que repercute profundamente na vida afetiva. E não se trata de um problema que afeta apenas alguns indivíduos, se trata, antes, de um traço característico de nosso tempo. Por isso o vazio existencial se manifesta como neurose coletiva (FRANKL, 2001a, p. 142), adquirindo proporções inimagináveis com repercussões no comportamento cultural.

\section{SINTOMAS DA NEUROSE COLETIVA}

Victor Frankl assinalou quatro sintomas para a neurose existencial, facilmente verificáveis nos dias de hoje. Manifestam-se como atitudes filosóficas diante da vida ou posicionamentos que as pessoas assumem frente à realidade, modos de agir mais ou menos perceptíveis na grande maioria dos sujeitos pósmodernos.

O primeiro sintoma surge como provisoriedade na conduta, atitude bastante comum em tempos de guerra. O soldado se sente constrangido a viver o momento presente por desconhecer o amanhã. E quem vive só o presente perde a dimensão de futuro. O homem pós-moderno adota atitude muito parecida. Sente-se inseguro quanto a um futuro de paz para a humanidade, temendo ameaças, como uma possível terceira guerra mundial, armas biológicas, doenças incuráveis, epidemias, desaparecimento de reservas de água doce, desastres naturais com gravíssimas consequências para a humanidade. Daí resulta a atitude provisória, causando apego ao aqui e agora como única garantia. Assim, o destino pessoal responsável é desconsiderado, como se tudo fosse fugaz e passageiro (FRANKL, 2001b, p. 62). As necessidades momentâneas são satisfeitas em detrimento da construção do futuro. Marcada pelo prazer do momento e indiferente ao resto, esta atitude se opõe à possibilidade de um objetivo na vida e à ideia de responsabilidade, porque se torna supérfluo se ocupar com que questões futuras (LUKAS, 1992b, p. 103). A situação caótica na 
qual a humanidade se encontra desperta o desejo de gozar o presente, aproveitando ao máximo cada instante de prazer.

Da atitude provisória deriva o segundo sintoma da neurose existencial: o fatalismo. Sem encontrar uma saída para seus problemas e sem esperança para o futuro, muitos acabam acreditando de maneira supersticiosa na força do destino que os arrasta. A visão mecanicista e biologista do ser humano o persuadem de que, na verdade, ele é apenas aparato instintivo, movido por reflexos condicionados. Não se vê mais como ser livre capaz de decidir, mas como alguém movido por sua própria natureza biológica. Tem pouca ou nenhuma responsabilidade sobre o que acontece, porque, em última análise, a culpa recai sobre o contexto social e as predisposições psicofísicas (FRANKL, 2001b, p. 62). A vida humana é regida por forças desconhecidas que definem o futuro; esse depende mais dos condicionamentos, dos astros, das energias cósmicas que da decisão humana. O que tem de ser será: assim pensa o fatalista que desiste de sua liberdade. Nesse caso, cruzar os braços e deixar que as coisas aconteçam por si mesmas desponta como a melhor saída para enfrentar o caos no qual vivemos (LUKAS, 1992b, p. 104).

O terceiro sintoma se encontra na atitude coletivista, que também não é de agora. Para Frankl, o nacional socialismo favoreceu de maneira extraordinária a mentalidade coletivista. Na Alemanha nazista essa mentalidade emergiu fortemente. $\mathrm{O}$ sentimento de pertença à nação alemã gerava um sentimento de superioridade em relação aos outros. Os judeus foram absurdamente desprezados, considerados pessoas inferiores e culpados pelos problemas socioculturais. Dentro dessa mentalidade houve muitas exceções, mas a opinião coletiva era mais forte. Tal mentalidade persiste com outros matizes, uma vez que muitas pessoas se deixam levar pela opinião da maioria. Quando todos pensam a mesma coisa sobre determinado assunto ou aspecto da vida, certamente é porque deve ser verdade. A mentalidade coletivista aliena a pessoa, liberando-a da tarefa de ter que pensar e encontrar a sua própria opinião e suas respostas aos problemas. Opiniões alheias a movem e servem de baliza para decisões pessoais, gestando um modo de vida que se cristaliza através da moda, do slogan, dos gostos da massa dominante (FRANKL, 2001b, p. 64). Quem se deixa vencer pela mentalidade coletivista, torna-se um ser impessoal, produto da coletividade, identificando-se com ideias de determinados grupos e perdendo sua originalidade, o que tem de mais próprio e inconfundível (LUKAS, 1992b, p. 106).

$\mathrm{O}$ último sintoma da neurose noogênica se define como fanatismo. $\mathrm{O}$ comportamento fanático se caracteriza, por sua vez, pela ignorância e desprezo 
da personalidade do outro. O fanático se apega à sua opinião, vista como verdade absoluta e indiscutível. Para Frankl, o totalitarismo levou o ser humano ao fanatismo, porque os líderes políticos fanáticos sempre foram capazes de qualquer coisa para atingir seus objetivos, segundo a convicção de que não há meios capazes de profanar os fins, pois todo meio se revela válido se leva a um fim desejado (FRANKL, 2001b, p. 65). Os adeptos do fanatismo têm normalmente um alvo à sua frente, mas querem alcançá-lo sem nenhum freio ou responsabilidade, tornando-se escravos do princípio do tudo ou nada, que acompanha todos os seus passos (LUKAS, 1992b, p. 107). Atualmente assistimos ao fanatismo do estado islâmico, eliminando os que não pensam da mesma forma, mesmo aqueles que pertencem à mesma religião. $\mathrm{O}$ fanático se torna fechado em suas ideias e pontos de vista, não conseguindo se abrir ao diálogo, a objetivos comuns, mas vivendo em função de seus ideais egoístas. A firme convicção de que o fim santifica os meios caracteriza a personalidade do fanático. Para Paul Tillich (2001):

O fanatismo é o correlato de auto-rendição espiritual: mostra ansiedade que supostamente estava dominada, atacando com violência desproporcionada àqueles que discordam e que demonstram, por sua discordância, elementos que o fanático deve suprimir ele mesmo de sua vida espiritual. Porque deve suprimi-los de dentro dele, tem que suprimi-los nos outros. Sua ansiedade força-o a perseguir os que dissentem. (TILLICH, 2001, p. 38).

\section{O MÉTODO LOGOTERAPÊUTICO PARA AFRONTAR O VAZIO EXISTENCIAL}

A Logoterapia de Frankl desenvolveu método próprio para tratar a neurose noogênica, causada pelo vazio existencial, para a qual, segundo o psiquiatra, a Psicanálise freudiana se mostra insuficiente. Segundo Freud, a terapia se baseia na análise dos sonhos e nas livres associações guiadas pelo analista, que convida o paciente a falar tudo o que lhe vem à mente para que emerja o inconsciente reprimido. É uma proposta que insiste na atividade psíquica inconsciente e nas experiências dos primeiros anos de vida como formadoras da personalidade (GOYA, 2001, p. 13). Os conflitos têm sua origem na infância, num confronto entre ego, superego e id. O que o superego reprime no id dá origem aos conflitos do ego. Daí a necessidade de escavar a história pessoal para solucionar problemas psíquicos. Tal método permanece válido, uma vez que sem tomar consciência dos mecanismos inconscientes que repercutem nas suas ações, o ser humano tem sua liberdade limitada por condicionamentos que provocam ilusões e comportamentos neuróticos (CATALAN, 1994, p. 20). 
Frankl, sem negar a contribuição de Freud, afirma que o surgimento da neurose noogênica deve alargar o horizonte da psicoterapia. Exatamente porque o contexto atual revela uma mudança no comportamento dos pacientes, o terapeuta não pode ignorar que, tantas vezes, os conflitos do cliente são existenciais. Não basta saber que as perplexidades, as dúvidas e o desespero da pessoa que sofre se desenvolveram de modo psicológico e a partir de mecanismos inconscientes. Ainda que seja possível e importante chegar às origens intrapsíquicas dos problemas do paciente, isso não basta para resolver o mal-estar que o invade. A análise não se reduz, assim, à reconstrução psicológica. Mais que isso, o terapeuta precisa também ser capaz de discutir com seu cliente o sentido da vida, afrontando os seus questionamentos quanto ao significado da existência. O neurótico necessita de uma crítica válida a seus pontos de vista negativos. Suas teses, influenciadas pela cultura materialista e niilista pós-moderna, que aprofunda ou até mesmo suscita suas neuroses, devem ser enfrentadas (FRANKL, 2001c, p. 46). Frankl insiste no valor da transcendência, como dimensão espiritual do ser humano, para reconstrução da saúde psicológica. Não basta a expressão das próprias necessidades e das potencialidades subjetivas. Para curar-se, a pessoa em conflito psicológico deve conferir sentido à própria vida com alguma coisa que está para além dela mesma, de seu ego doente. Essa atitude se opõe ao comportamento da pessoa neurótica que observa a si mesma exageradamente, buscando 100\% de certeza em seus conhecimentos e em suas decisões (FRANKL, 2001a, p. 118). Por estar sempre atento a si mesmo, "o neurótico carece de uma disposição para amar" (LUKAS, 2002, p. 30).

O termo Logoterapia se refere a logos, é a terapia que faz encontrar o logos, ou seja, o sentido da situação para além do próprio eu. Daí que conceitos fundamentais da Logoterapia de Frankl sejam liberdade e responsabilidade, fenômenos especificamente humanos que remetem à capacidade de autotranscedência. Princípios fundamentais da dimensão noética da existência, que permitem que a pessoa saia de si mesma em direção a uma tarefa e ao amor. Enquanto permanece presa a suas necessidades hedonistas e egoístas, sente-se vazia e adoece psicologicamente. Só abrindo-se a um sentido que implica tarefas realizáveis, que têm a ver com a alteridade, a realização de um projeto válido em si mesmo, a pessoa consegue reaver saúde e enfrentar corajosamente as dificuldades da vida. A autotranscedência se manifesta na vontade de sentido que faz encontrar significado para a própria vida. Esta vontade, diversa da vontade de prazer e da vontade de poder, formuladas pela Psicanálise e pela 
Psicologia Individual, se encontra na base da teoria de Frankl (GISMONDI, 1990, p. 152-154).

\section{PSICOLOGIA, ESPIRITUALIDADE E SAÚDE SEGUNDO A LOGOTERAPIA}

Para Frankl, Psicologia e Religião ou espiritualidade respondem a aspectos diferentes da existência humana. O objetivo da Psicologia se encontra na cura psíquica da pessoa humana, enquanto a Religião busca a salvação e o significado último da existência. A perspectiva religiosa vai além da Psicologia, a qual não está equipada para enfrentar questões sobre a plausibilidade de um sentido último. A Logoterapia, no entanto, reconhecendo a demanda de sentido que habita o coração humano procura levar a sério a problemática religiosa, admitindo que a religião ofereça condições de ajudar a encontrar respostas para as necessidades mais radicais da humanidade. E uma vez que o homem é livre e responsável diante de sua existência e a percebe, referida não somente a alguém ou a alguma coisa, mas também ao totalmente outro, a religião integra parte da sua vida.

Para o psiquiatra vienense, a religião se situa na consciência, que ele chama de órgão de sentido, responsável pelas decisões existenciais que todo ser humano toma ao longo de sua vida. "Ela pertence incondicionalmente ao ser humano "como ser que decide" (FRANKL, 1997, p. 26). A tarefa primordial da consciência consiste em harmonizar a lei moral eterna concebida de forma geral com as situações concretas e particulares da pessoa (FRANKL, 1997, p. 28). Lei eterna não se identifica com a lei natural da moral cristã, mas diz respeito à percepção de um sentido último que se concretiza em valores criativos para o bem comum e está voltada para o que realmente importa para a existência única e individual. A consciência produz tensão entre ser e deve ser e essa tensão remete à possibilidade da transcendência, a um sentido último ao qual o ser humano se sente referido e o inclina para o bem. Se para a recuperação da saúde o homem neurótico precisa transcender o seu próprio ego em direção a uma tarefa, aqui ele transcende a si mesmo de maneira radical ao estabelecer relação pessoal com o mistério indizível, onde a consciência emerge como a voz da transcendência, algo distinto da limitação do próprio eu, que situa o ser humano para além de seus monólogos interiores, fazendo-lhe descobrir um interlocutor secreto e misterioso (FRANKL, 1997, p. 41).

A logoterapia se interessa pela dimensão espiritual do ser humano, inscrita em sua capacidade de ultrapassar a si mesmo para realizar uma tarefa que dê sentido à sua vida. Frankl acrescenta, assim, o espiritual ao psicológico, 
afirmando, inclusive, a existência de um espiritual inconsciente onde se dá a relação com Deus, que não anula a decisão do ser humano a favor do sentido, mas que exige participação ativa da consciência como órgão da decisão. Ainda que a consciência seja a presença do transcendente no ser humano, o órgão do sentido, a liberdade final depende sempre do sujeito (FRANKL, 1997, p. 50). Frankl cunhou o conceito de inconsciente espiritual, buscando mostrar a presença do espiritual no próprio inconsciente, que não se reduz ao instintivo, ao id, como quer a Psicanálise (FRANKL, 1977, p. 48). Para o psiquiatra (1997, p. 48), "sempre houve em nós uma tendência inconsciente em direção a Deus, sempre tivemos uma ligação intencional, embora inconsciente, com Deus”. O ser humano está, portanto, numa relação implícita com o mistério absoluto que chamamos Deus, o que não quer dizer que Deus habite o inconsciente. $O$ pensamento de Frankl encontra um eco teológico no conceito de existencial sobrenatural da teologia de Rahner, para quem a graça de Deus toca o ser humano em sua ontologia, garantindo-lhe sua estrutura ontológico-vertical e ordenando-o à comunhão com Deus. Mesmo não sendo atribuível à natureza humana, por ser dom gratuito, o ser humano se caracteriza como potentia oboedientialis, ou seja, chamado desde o mais íntimo do seu ser à união com Deus (RAHNER, 2008, p. 157-165). De alguma maneira, o ser humano se percebe referido à transcendência, o que, segundo Frankl, repercute no seu inconsciente.

Frankl discorda das teorias psicológicas que tendem a reduzir a psique a um reservatório de funções psíquicas, onde colidem sentimentos, agressividade, frustrações, anseios, temores, complexos. $O$ especificamente humano permanece oculto nessa visão. O psiquiatra vienense redescobre o espírito3, a dimensão noética do ser humano que o torna capaz de abraçar valores e encontrar sentido. Em sua Logoterapia, o conceito de psique se abre à dimensão espiritual (LUKAS, 1990, p. 156). Seu pensamento, nesse aspecto, apresenta novidade, pois se afasta de teorias psicológicas nas quais a religiosidade se explica como expressão de processos psíquicos ancorados em conflitos da infância não superados ou numa instintiva busca de proteção marcada pelo medo da morte. De fato, a religiosidade humana sofre ampla suspeita psicoterapêutica. Frankl acolhe a dimensão religiosa do ser humano, sem querer

$3 \mathrm{O}$ termo espírito na Teologia cristã se refere à dimensão transcendental do ser humano que o torna aberto à comunicação de Deus. Sua vida não se reduz ao aspecto físico-biológico, mas carrega uma dimensão ôntico-transmaterial que o projeta para além de si mesmo rumo à verdade última que chamamos Deus. $\mathrm{O}$ ser humano é, ao mesmo tempo, corpo e espírito ou corpo e alma, dimensões essenciais e inseparáveis do seu ser (DE LA PEÑA, 1988, p. 140-141). Na Logoterapia, espírito se refere também à dimensão transcendente do ser humano, ainda que o termo não seja compreendido na mesma acepção da Teologia cristã. Espírito é o que no ser humano vai além do psiquismo, projetando-o para a transcendência. 
explicá-la de forma definitiva pela psicologia. Além de sua constituição psíquica, o ser humano carrega dimensão espiritual que evidencia seu anseio pelo sentido, como constatamos na história das religiões e dos mitos; ao questionar a razão de sua própria existência em sentido último, revela sua dimensão espiritual que nenhuma escola de psicologia deveria repelir como patológica e desnecessária (BATTHYABY apud FRANKL; LAPIDE, 2013, p. 42-44).

Para Frankl, Jung teve o mérito de descobrir a dimensão religiosa do inconsciente, mas a situou na região instintiva do id, tirando o religioso da responsabilidade do eu. $\mathrm{O}$ id, nesse caso, impulsionaria o ser humano ao religioso, sem que lhe fosse exigida uma decisão pessoal. $O$ inconsciente religioso para Frank apenas existe no ser humano sem que se determine como impulso, pois carrega consigo a exigência da decisão. As imagens religiosas não constituem arquétipos latentes; são, na verdade, recebidas do ambiente cultural-religioso no qual nascemos. As concepções de Deus se encontram presentes nas diversas culturas sem que sejam arquétipos inatos. Nessas concepções o homem expressa sua dimensão espiritual (FRANK, 1997, p. 51).

Quanto a Freud, Frankl não concorda que a religião seja a neurose obsessiva da humanidade a ser superada no futuro. Hoje não se fala mais de futuro de uma ilusão, reflete-se, ao contrário, sobre a eternidade de uma realidade, visto que a religião é dado empírico cada vez mais estudado pela Teologia e Ciência das Religiões. Se, por um lado, a neurose surge como consequência de mecanismos inconscientes que necessitam ser descobertos, por outro existe também a repressão da transcendência no inconsciente, que emerge na análise como inquietação do coração e se manifesta como neurose. Além de impulsos reprimidos, há no inconsciente uma religiosidade reprimida também capaz de provocar neurose (FRANKL, 1997, p. 52). Se para Freud a religião é a neurose obsessiva da humanidade nascida no relacionamento com o pai (complexo de Édipo), exaltado por infantilismo psíquico como Deus, para Frankl também o inverso se mostra verdadeiro, ou seja, em muitos casos, "a neurose obsessiva é que seria a religiosidade psiquicamente doente” (FRANKL, 1997, p. 53), causada pela deficiência do transcendente.

Em seu trabalho de análise de pacientes com sintomas neuróticos, Frankl constatou que em muitos deles a relação com a transcendência estava profundamente perturbada ou mesmo reprimida. Nesse caso, o processo de cura dependeu do restabelecimento da dimensão espiritual da própria vida, a partir da retomada da relação com a transcendência. O psiquiatra (1997, p. 54) reporta a fala de alguns de seus clientes. Um deles declarou: "Os homens são claramente ligados à natureza e a Deus, embora não saibam disso”. Outro, 
descrevendo seus sonhos, relatou: "Nos sonhos, muitas vezes, caía num pranto libertador e conciliador que nunca havia experimentado em estado de vigília”. Outro foi ainda mais incisivo: "Eu sou a comprovação médica de que não se pode viver sem Deus”.

Religião e Logoterapia giram em torno da questão do sentido. Para além do sentido de situações específicas, o ser humano busca o sentido da totalidade, que abrange todos os aspectos da vida num conjunto que tenha significado (SCHILLEBEECKX, 2012, p. 221). Enquanto a religião descobre o sentido último a partir da revelação4, de um mais além, a Logoterapia o afirma a partir do mais aquém, situando-se, portanto, antes do salto da fé, exigido do homem que crê. Mas a fé no significado postula, de certo modo, a transcendência do ser humano. Somente a partir dela ele avança para uma dimensão mais alta da sua própria vida. Para além do significado de uma tarefa que ele possa assumir com sentido para superar possíveis conflitos psicológicos e neuroses, está também em condições de compreender o sentido "da totalidade", o qual tem potencial para iluminar sua vida e seu sofrimento (FIZZOTTI; SALUSTRI, p. 225).

Para muitos seres humanos, o sentido da vida assume uma dimensão transcendental percebida desde uma interioridade onde se dá o conhecimento de Deus. Para Frankl, o caminho para Deus tem caráter ontológico, ou seja, o ser humano se dá conta de um sentido mais originário para sua vida, se percebe referido a um horizonte último que o envolve. Não sendo a origem de si mesmo, está referido a um mistério maior. Ele se vê, assim, com uma demanda metafísica, pois sua vida não se restringe à sua dimensão físico-biológicopsíquica. Tal demanda se revela, ao mesmo tempo, teórica e afetiva. "No fundo do nosso ser há uma nostalgia que só pode referir-se a Deus" (FRANKL, 2001b, p. 119). Essa nostalgia se inscreve na dinâmica do desejo e confere à vida relevância metafísica. Partindo do desejo - emoção - que projeta o ser humano para fora de si mesmo, ele pode chegar à dimensão transcendente. $O$ pressuposto para tal descoberta é não reprimir seu desejo transcendental.

O caminho para Deus, na proposta de Frankl, se fundamenta na livre decisão para crer. A opção religiosa autêntica supõe liberdade. A espiritualidade verdadeira nasce onde não há constrangimentos. Seu potencial de cura psíquica, no entanto, emerge sempre como efeito colateral, uma vez que seu objetivo é teológico e diz respeito à salvação do ser humano. A espiritualidade não garante

\footnotetext{
$4 \mathrm{O}$ termo revelação faz referência à autocomunicação de Deus ao ser humano. Nesse sentido, "a religião é, em definitivo, a tomada de consciência da presença do Divino no mundo” (QUEIRUGA, 2010, p.25). Para os cristãos, a revelação de Deus ao ser humano acontece através da escolha do povo de Israel e chega à sua plenitude em Jesus Cristo, o que não exclui que haja revelação em outras tradições religiosas.
} 
ausência de conflitos psicológicos. Psicologia e religião são campos diferentes e "deve ser evitada com todo rigor qualquer contaminação entre estes dois campos, que podem até coincidir quanto a seus efeitos, mas são diferentes quanto à sua intencionalidade" (FRANKL, 1997, p. 57).

A Psicologia se caracteriza como scientia naturaliter irreligiosa e conserva sua autonomia, ainda quando define o ser humano como anima naturaliter religiosa (FRANK, 1997, p. 58). O psiquiatra se opõe a uma religião considerada profilaxia para todo tipo de problema físico ou psíquico, pois sua intenção não é essa, o que não quer dizer que não produza efeitos psicoterapêuticos. Ela oferece ao ser humano sensação de proteção e sentido que só se encontra no Absoluto, em Deus, o que a torna um dispositivo de integração psíquica. O contrário também parece verdadeiro. A terapia faz o cliente se reencontrar com fontes de seu próprio ser reprimidas e inconscientes que o levam em direção à fé em Deus (FRANKL, 1997, p. 59). Nesse caso, “a religião pode, sem querer, contribuir para a cura psíquica de uma pessoa, ou a psicoterapia, também sem querer, pode capacitar o ser humano para a busca de um sentido religioso" (LUKAS, 1990, p. 156). Exatamente esse sem querer garante a autonomia da religião e da Psicologia. A descoberta da espiritualidade se revela uma aventura do próprio cliente e não imposta pelo psicoterapeuta. A espiritualidade diz respeito a uma dimensão mais abrangente da existência e só é alcançável pela fé e não pela ciência. Fé que nasce da liberdade, não da imposição dos pais ou do contexto cultural. A fé verdadeira, enquanto relação assumida com Deus brota da liberdade interior e exclui obrigação.

Frankl sofre críticas por afirmar a existência da religiosidade na estrutura psíquica do ser humano com o seu conceito de inconsciente espiritual (CATALAN, 1994, p. 17). Por outro lado, seu esforço para não confundir Psicologia com Religião parece claro. Ele apenas afirma que Psicologia e espiritualidade se encontram como dimensões do ser humano. Hoje assistimos a uma espiritualização da doença que engendra uma fé mágico-supersticiosa. Não é incomum ouvir pregadores cristãos, por exemplo, afirmar que problemas psicológicos e físicos são causados por falta de fé. Ao invés dos dispositivos normais da Medicina e da Psicologia, muitas pessoas buscam curas milagrosas em eventos religiosos catárticos. A fragilidade emocional acaba sendo instrumentalizada pela lógica da manipulação e instrumentalização, que tornam as pessoas vítimas da exploração através da espiritualidade. Aqui, a relação entre espiritualidade e Psicologia permanece patológica, porque a Religião assume o lugar que seria da Psicologia ou da Psiquiatria. 
A relação entre espiritualidade e saúde psíquica à luz da Logoterapia de Frankl apresenta mais plausibilidade. A pessoa que cultiva uma espiritualidade autêntica, uma saudável relação com Deus, está em condições de se afastar interiormente de suas circunstâncias, sejam elas quais forem. Se não pode resolvê-las, ao menos pode adotar atitudes interiores frente às circunstâncias, evitando o mecanismo neurótico que tende a levar a pessoa à identificação patológica com a própria doença. Quem toma distancia interior de uma doença, seja psíquica ou mesmo física, tem mais chances de superá-la do que aquele que vê sua vida resumida à doença. $\mathrm{O}$ espiritual se constitui como aquela parte do ser humano que, por assim dizer, não adoece nunca e reage sempre contra possíveis enfermidades. A confiança no mistério último que chamamos Deus produz confiança para enfrentar dificuldades da vida, inclusive as de ordem psíquica, que ficam minimizadas frente ao significado maior para a vida aportado pela espiritualidade ou fé religiosa (LUKAS, 1990, p. 158-163).

$\mathrm{O}$ homem religioso que cultiva a espiritualidade e desenvolve sensibilidade ética se encontra mais equipado de dispositivos interiores que o ajudarão a compreender as circunstâncias da sua vida, ainda que trágicas. Estando menos centrado em si mesmo, se sente capaz de incluir o outro, a cultura, seus próprios valores como conteúdos de criação. A espiritualidade, quando autêntica, contribui para atenuar os efeitos nocivos do egocentrismo pós-moderno causador de doenças psíquicas, porque capacita o ser humano para o amor, a partilha, a solidariedade. E ainda que haja condicionamentos inconscientes ou sociais, a dimensão espiritual qualifica o ser humano para uma reação consciente a tendências negativas herdadas ou adquiridas (LUKAS, 1990, p. 166).

A espiritualidade se torna uma força motriz de crescimento e cura, porque põe a pessoa em movimento para fora de si mesma. Caminho bem diferente daquele seguido por certas espiritualidades de massa da pós-modernidade, que querem apenas trazer consolo, conforto e segurança, tornando Deus (a transcendência) mero meio para atingir um fim: a realização de desejos e necessidades egoístas e marcadamente narcísicas. Infelizmente, em nosso contexto, parece ser esse o traço coletivo mais marcante da espiritualidade que, em sua acepção mais saudável e autêntica, supõe encontro com uma realidade outra que descentraliza das projeções e exigências pessoais infantis. A saúde psíquica que a espiritualidade permite alcançar, segundo a Logoterapia, é aquela que ajuda a pessoa a se encontrar consigo mesma, favorecendo outro olhar sobre seu passado, sua situação atual e sobre o mundo à sua volta. A espiritualidade postula sempre o encontro com a transcendência, no mais 
profundo do próprio eu, ou seja, na imanência, modificando a relação da pessoa com o mundo e os outros. O perdão, por exemplo, se encontra no coração de toda experiência espiritual verdadeira. Também acontece fora da experiência religiosa, mas essa o potencializa, criando condições para que brote do mais íntimo da pessoa. "Quem perdoa de coração e sinceramente põe um ponto final e limpa todo um período de sua vida das ramificações da erva daninha do ódio" (LUKAS, 2002, p. 51). De fato, se trata de uma experiência libertadora que faz a pessoa seguir o seu caminho livre de pesos e de modo adulto, sem fixações inúteis no passado e em pessoas que lhe causaram dano emocional. A saúde psíquica não decorre, no entanto, de um toque de varinha mágica, como são as orações supersticiosas, mas engaja a liberdade e a responsabilidade da pessoa, que decide, à luz de uma espiritualidade, redirecionar sua vida.

\section{CONCLUSÃO}

Para Victor Frankl, além das pulsões inconscientes, há no ser humano uma vontade de sentido que, quando não realizada, acentua os distúrbios psicológicos e até os provoca. Com o niilismo pós-moderno, surgiu a neurose noogênica, que se manifesta como neurose cujo sintoma mais expressivo é a frustração de sentido ou vazio existencial. A elaboração dos conflitos psíquicos, segundo o método de Frankl, passa também pela descoberta do sentido em cada situação específica, mesmo no sofrimento, o que exige liberdade e responsabilidade, uma vez que o sujeito não apenas sofre os impulsos inconscientes ou os condicionamentos sociais; enquanto ser consciente, cabelhe tomar posição frente ao que lhe acontece, a partir de valores criativos, experienciais e atitudinais. $\mathrm{O}$ especificamente humano se encontra na liberdade que remete à consciência, órgão de sentido que faz perceber os valores da existência através da autotranscendência, que o torna capaz de ultrapassar o seu próprio eu na descoberta de uma tarefa a realizar.

Victor Frankl postula a possibilidade da descoberta de um supra-sentido. Sua Logoterapia se interessa pela questão da espiritualidade, uma vez que o sentido se encontra no coração da experiência religiosa. A vontade de significado faz despontar a questão do sentido último, que abarca a totalidade da existência. Ainda que a descoberta do sentido de cada situação não exija a fé religiosa, Deus pode ser encontrado como parceiro do ser humano, uma vez que, segundo Frankl, o inconsciente carrega uma dimensão espiritual que, ao emergir, contribui para o equilíbrio psíquico e existencial. Frankl define Deus como "o interlocutor dos nossos mais íntimos solilóquios” (FRANKL, 2001b, p. 
100), mas não entra na questão das religiões, nas quais a relação com Deus se expressa. A Logoterapia, como outras escolas de Psicologia, não visa à espiritualidade, mas à dimensão psíquica-existencial da pessoa. A descoberta da dimensão espiritual emerge, no entanto, como uma possibilidade, capaz de ajudar o sujeito na reconstrução de seu equilíbrio psíquico-existencial. Mas ela só é saudável quando descentra a pessoa de si mesma, de seus conflitos interiores numa experiência de autotranscendência que desperta um novo olhar sobre a vida e o sofrimento. Não obstante seus limites (FIZZOTTI, 2002, p. 206207), a contribuição da Logoterapia de Frankl tem pertinência indiscutível e se mostra à altura dos desafios atuais, marcados pelo niilismo dos valores e pela revalorização da religiosidade.

A visão de Frankl sobre a interface entre espiritualidade e saúde se distancia da Psicanálise, que avalia a Religião a partir das condições psíquicas do sujeito. No entanto, psicanalistas atuais, mais abertos à experiência religiosa, alertam para seus riscos que, ao invés de torná-la um elemento que contribui para a saúde psíquica, pode acentuar a neurose. Seu posicionamento não contradiz a postura mais positiva de Frankl, antes a aprofunda. Para esses psicanalistas, quando Deus é experimentado como mero complemento de nossas necessidades, torna-se uma fantasia que não favorece o crescimento, ao contrário, se transforma no mais profundo obstáculo para o verdadeiro encontro com ele (MORANO, 1998, p. 46). Catalan cita Freud (2003, p.55): "Uma crença é um ilusão quando, na sua motivação, a realização de um desejo prevalece e, por causa disso, não é possível estabelecer a relação desta crença com a realidade. A própria ilusão se recusa a ser confirmada pelo real". A verdadeira experiência de Deus não coincide com a projeção dos próprios medos e desejos, como prolongamento do narcisismo, porque, nesse caso, o Tu ao qual o sujeito se dirige se transforma num espelho em que procura recuperar a maltratada onipotência infantil, um instrumento com o qual quer dar fundamento à sua própria neurose. A espiritualidade corre o risco de se tornar um jogo imaginário, que não permite o encontro com a transcendência e com o real (MORANO, 1998, p. 55). Segundo a Logoterapia, se a espiritualidade não provoca a autotranscendência do eu narcísico e neurótico, também não é saudável e não ajuda na recuperação do equilíbrio psíquico, porque acaba reforçando o que deveria evitar. 


\section{REFERÊNCIAS}

CATALAN, Jean-François. Esperienza spirituale e Psicologia. Milano: San Paolo, 1994.

DE LA PEÑA, Juan L. Ruiz. Imagen de Dios. Antropolía teológica fundamental. Santander: Sal Terrae,1988.

LAGLE, Alfried. Viver com sentido. Petrópolis: Vozes/Sinodal, 1992.

LIBANIO, João Batista. A religião no início do milênio. São Paulo: Loyola, 2002.

LUKAS, Elisabeth. Mentalização e saúde. Petrópolis: Vozes, 1990.

LUKAS, Elisabeth. Assistência logoterapêutica. Petrópolis: Vozes/Sinodal, 1992a.

LUKAS, Elisabeth. Prevenção psicológica. Petrópolis: Vozes/Sinodal, 1992b.

LUKAS, Elisabeth. Psicologia espiritual. São Paulo: Paulus, 2002.

FIZZOTTI, Eugenio; SALUSTRI, Massimo. Psicologia della religione. Con antologia dei testi fondamentali. Roma: Città Nuova, 2001.

FIZZOTTI, Eugenio. Logoterapia per tutti: guida teorico-pratica per chi cerca il senso della vita. Catanzaro: Rubbettino, 2002.

FRANKL, Victor. Um sentido para a vida: psicoterapia e humanismo. Aparecida: Santuário, 1989.

FRANKL, Victor. Senso e valori per l'esistenza. Roma: Città Nuova, 1994.

FRANKL, Victor. A presença ignorada de Deus. Petrópolis: Vozes/Sinodal, 1997.

FRANKL, Victor. Senso e valori per l'esistenza. La risposta della Logoterapia. Roma: Città Nuova, 1998.

FRANKL, Victor. Teoria e terapia delle nevrosi. Brescia: Morceliana, 2001a.

FRANKL, Victor. Homo patiens: soffrire com dignità. Brescia: Queriniana, 2001b.

FRANKL, Victor. Logoterapia e analisi esistenziale. Brescia: Morceliana, 2001c.

FRANKL, Victor. Em busca de sentido. Petrópolis: Vozes/Sinodal, 2006.

FRANKL, Victor; LAPIDE, Pinchas. A busca de Deus e questionamentos sobre o sentido. Petrópolis: Vozes, 2013.

GOYA, Benito. Psicologia e vita spirituale: sinfonia a due mani. Bologna: EDB, 2001. 
GISMONDI, Angelo. Il paradosso terapeutico secondo la logoterapia. In:

Logoterapia applicata. Da una vita senza senso a un senso nella vita.

FIZZOTTI, Eugenio; CARELLI, Rocco. (orgs.) Roma: Città Nuova, 1990.

MORANO, Carlos Domínguez. Orar depois de Freud. São Paulo: Loyola, 1998.

QUEIRUGA, Andrés Torres. Repensar a revelação: a revelação divina na realização humana. São Paulo: Paulus, 2010.

RAHNER, Karl. Curso fundamental da fé. São Paulo: Paulus, 2008.

SCHILLEBEECKX, Edward. História Humana: revelação de Deus. São Paulo:

Paulus, 2012.

TILLICH, Paul. A coragem de ser. São Paulo: Paz e Terra, 2001.

VOLPI, Franco. O niilismo. São Paulo: Loyola, 1999. 